\title{
Brown tumors simulating metastases on FDG PET in a patient with parathyroid carcinoma
}

\author{
Berith Kemps • Henriette Quarles van Ufford • \\ Wouter Creyghton • Marie de Haas • \\ Henk Jan Baarslag • Inne Borel Rinkes • John de Klerk
}

Received: 15 November 2007 / Accepted: 26 December 2007 / Published online: 12 February 2008

(C) Springer-Verlag 2008

A 48-year-old man presented with nausea, fatigue, shoulder and back pain. Laboratory showed raised serum calcium and parathyroid hormone (PTH) levels, $4.49 \mathrm{mmol} / 1$ (normal, 2.10-2.75 $\mathrm{mmol} / \mathrm{l}$ ) and $194 \mathrm{pmol} / \mathrm{l}$ (normal, 5-5 pmol/1). Standard X-rays revealed multiple suspicious osteolytic lesions, and under the suspicion of metastatic disease, a CT scan of neck, thorax and abdomen and a whole-body $18 \mathrm{~F}$ fluorodeoxyglucose (FDG) positron emission tomography (PET) were performed. These scans demonstrated multiple osteolytic lesions with high uptake of FDG (a, arrows) and a lesion in the left parathyroid gland with slightly elevated FDG uptake. Histological biopsy of a lytic lesion in the os ilium revealed brown tumour, and parathyreoidectomy revealed a parathyroid carcinoma. Parathyroid carcinoma is a very rare cause of PTH-dependent hypercalcaemia, accounting for less than $1 \%$ of all cases of hyperparathyroidism [1]. In primary hyperparathyroidism, brown tumour, or osteitis fibrosa cystica, is an uncommon bone disease and usually occurs in patients in advanced stages of the disease [2-4].

Subsequently, the patient developed severe pain in the neck with neurological symptoms and a MRI was per-

B. Kemps $(\bowtie) \cdot$ M. de Haas $\cdot$ H. J. Baarslag $\cdot$ J. de Klerk Radiology and Nuclear Medicine, Meander Medical Centre, Amersfoort, Netherlands

e-mail: berithke@hotmail.com

H. Quarles van Ufford

Radiology and Nuclear Medicine,

University Medical Centre Utrecht,

Utrecht, Netherlands

\section{W. Creyghton}

Department of Internal Medicine, Sint Jansdal Hospital, Harderwijk, Netherlands

I. Borel Rinkes

Department of Surgery, University Medical Centre Utrecht, Utrecht, Netherlands formed to evaluate the cervical myelum. Pathologic signal intensity in corpus C3 extending in the pedicles (b, arrow) was seen. Software fusion (Siemens, trueD) of the PET and MR images was performed (c). Because the patient suffered from parathyroid carcinoma, metastasis was suspected. A second biopsy was performed by the orthopaedic surgeon, and pathology revealed another brown tumour. It is known that the radiographic presentation of brown tumours is very similar to that of metastatic disease. The present case illustrates high FDG uptake of brown tumours, resembling metastatic bone disease which leads to diagnostic pitfalls.
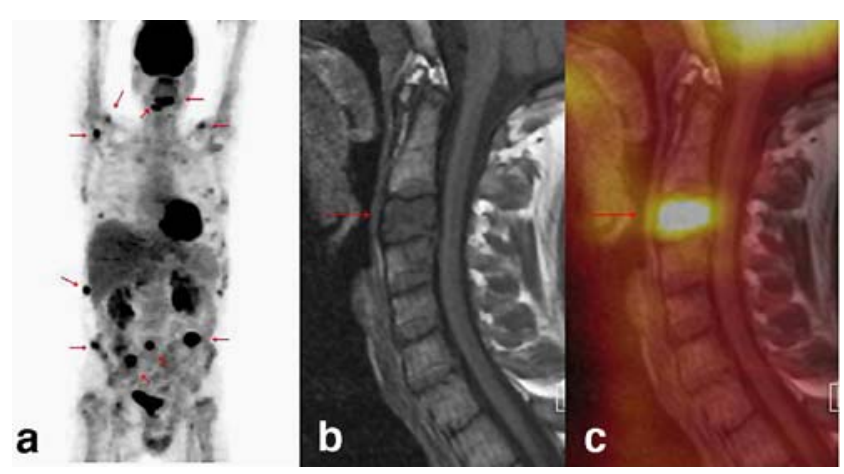

\section{References}

1. Tan G, Shiran M, Swaminathan M, Phang K, Rohaizak M. Large retrosternal parathyroid carcinoma with primary hyperparathyroidism. Asian J Surg 2007;30(4):286-9.

2. Kocher M, Gebhardt M, Jaramillo D, Perez-Atayde A. Multiple lytic skeletal lesions and hypercalcaemia in a 13-year-old girl. Clin Orthop 2000;374:298-319.

3. Mankin H. Metabolic bone disease. J Bone Joint Surg Am 1994;76:760-86.

4. Scully R, Mark E, McNeely W, McNeely B. Case records of the Massachusetts General Hospital. 1993:328;1031-35. 